\section{Microscopy and Imaging of Foods- The Whys and Hows}

\author{
Paula Allan-Wojtas \\ Agriculture and Agri-Food Canada \\ allanwojtasp@agr.gc.ca
}

The use of microscopy and imaging methods to study foods is not a new idea. It has been going on since the first light microscopes were developed (White, 1970; White and Shenton, 1974-1984). Microscopy has been used to determine the quality, purity and safety of foodstuffs by detecting and identifying contaminants in foods. The short article by Stephen Carmichael in the May/June 2002 issue of Microscopy Today has again brought food microscopy into the spotlight. The article provided an opportunity to discuss present applications of food microscopy and to give some projections of where it is headed in the future. The reader may not realize that microscopy and imaging methods are used extensively by most major food companies worldwide for product development, quality control, and trouble shooting (Allan-Wojtas, 1999). Often, this work cannot be published because it contains proprietary information. The application of microscopy to food structure analysis is one of the best kept secrets in microscopy today.

\section{Why use microscopy to study food?}

There is no doubt that the most comprehensive library of images and applications of food microscopy available today exists at the "Foods Under the Microscope" website, by Dr. Miloslav Kalab, ${ }^{1}$. referred to in the Microscopy Today article cited above. The reader is referred to the website for a host of images and some introductory background and historical comments.

As microscopists, all of us understand the power of a technique where the results are in the form of pictures. Pictures can convey information in a manner that numbers and charts cannot. This is particularly useful when we explain differences between a "good" product and a "bad" product to food manufacturers, who often have little scientific background. Image analysis techniques can quantify structural information from these images to convert it into a numerical form for food technologists and engineers to use. As in all applications of microscopy, the microscopical analysis of food is as subjective as the researcher. It depends on the experience of the researcher, and the tools and equipment available. The range of food samples that we study covers natural to manufactured foods, and includes all handling steps from production of raw materials to consumption by the consumer. Effective use of microscopy as a food analysis tool assumes a broad background in many interrelated fields. The analysis of food using microscopy takes a multidisciplinary approach where all data, including microstructural information, is integrated into a comprehensive description of the food system of interest. The unique contribution that microscopy can provide can help explain data which appears to be inconsistent with what was expected or assumed (Allan-Wojtas et al., 2003).

\section{What can you learn from using microscopy to study food structure?}

Microscopy can be applied to different extents depending on the information and detail required. We now define some key terms related to this approach. "Food Microscopy" is a general term that describes the use of microscopy to obtain a magnified look at foods of interest. Examples of this application include identification and measurement of components or ingredients in foodstuffs and detection and identification of contaminants (Flint, 1994).
"Food microstructure" encompasses the systematic use ur mIcroscopy to describe the structures and interrelationships among cells and tissues in situ at a number of magnifications, that is, the microstructural hierarchy of the food (Vaughan,1979; Aguilera and Stanley, 1999). The microstructural hierarchy can indicate the types and size ranges of microstructural elements that make up the food. A good example of this application is in describing the fruit, tissue, and cell architecture of a fresh apple. It is also possible to use microscopy in this way to describe the effects of processing on these structures in the apple.

"Food structure and functionality" relates levels of the food structure hierarchy to the behaviour of a food assessed through traditional analytical methods such as mechanical testing (such as compression), sensory evaluation ("taste testing") and chemistry. This approach provides an integrated description of how structure affects texture and behaviour of the food at each level in the hierarchy. This approach is used, for example, to describe the relationship between the arrangement of tissues and cells in an apple and its texture (Allan-Wojtas et al., 2003; Aguilera and Stanley, 1999).

"Food structuring" is an approach that describes how the relationships between food structure and functionality are used to manipulate food to obtain a desired texture (Aguilera and Stanley, 1999). We assume that samples with similar microstructures will have similar textures. Examples where this application is used is the manufacture of foods including product development, process optimization, and engineering of foods with defined characteristics.

\section{How is a food sample different from a biomedical sample?}

Food can take many forms in the journey from "farm to fork", ranging from food that looks very similar to its biological raw material (plants and animals) to a form where its biological origin is not apparent (tofu, dairy products, sausage). As food microscopists, we are interested in the basic structure of food, and how it changes as it proceeds through all the steps until it reaches the consumer (Table 1). Structure is either breaking down (e.g., various degrees of cell and organelle disruption during ripening and senescence of fruit or ageing of meat), or being built up (e.g., a manufactured
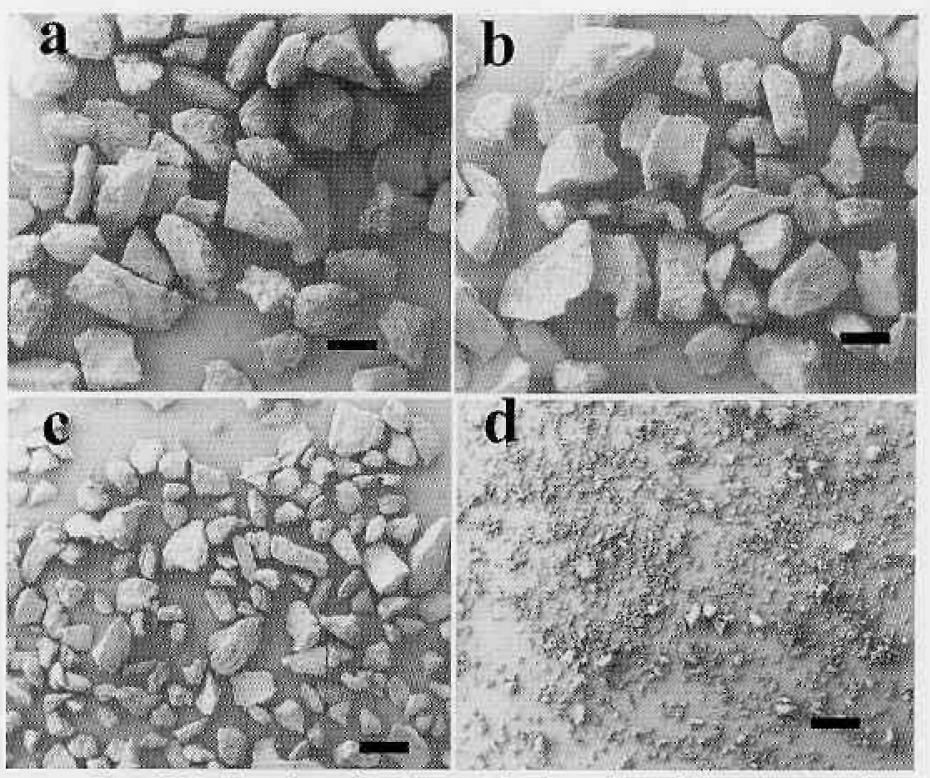

Fig. 1 SEM of sieved samples of cormmeal and cornflour of decreasing particle size. (cormmeal: $a, b$, and $c$; cornflour, d). Grittiness (also called sandiness or graininess) is a sensory characteristic of food products which is easy to determine by mouthfeel but is not favoured by consumers. The perception of grittiness is related to particle size, shope and orientation. Microscopy provides actual measurement of particle sizes as well as information on particle shape and smoothness. Bars $=500 \mu \mathrm{m}$ 


\section{LEO's New Microscopes Answer All Your EM Needs}

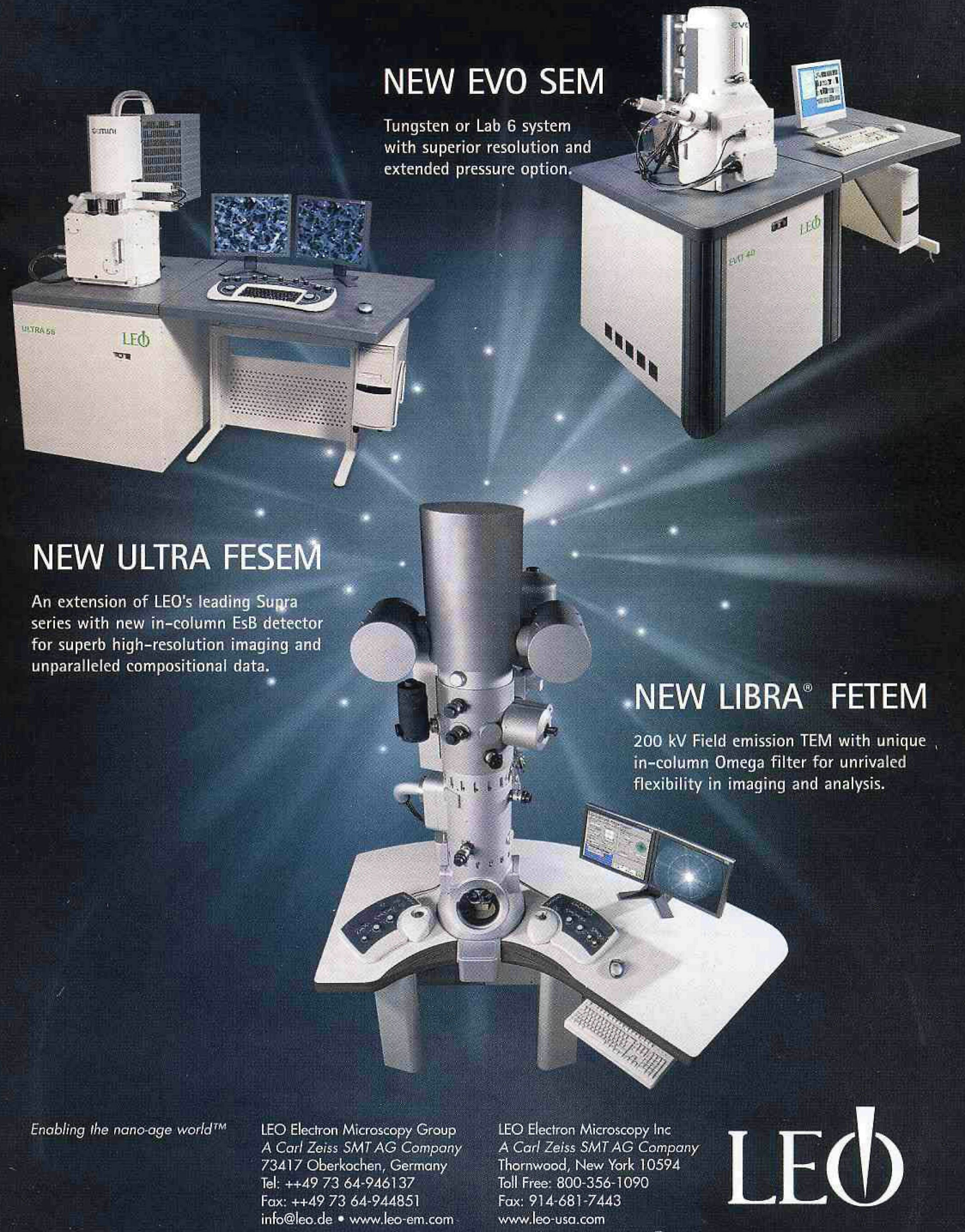




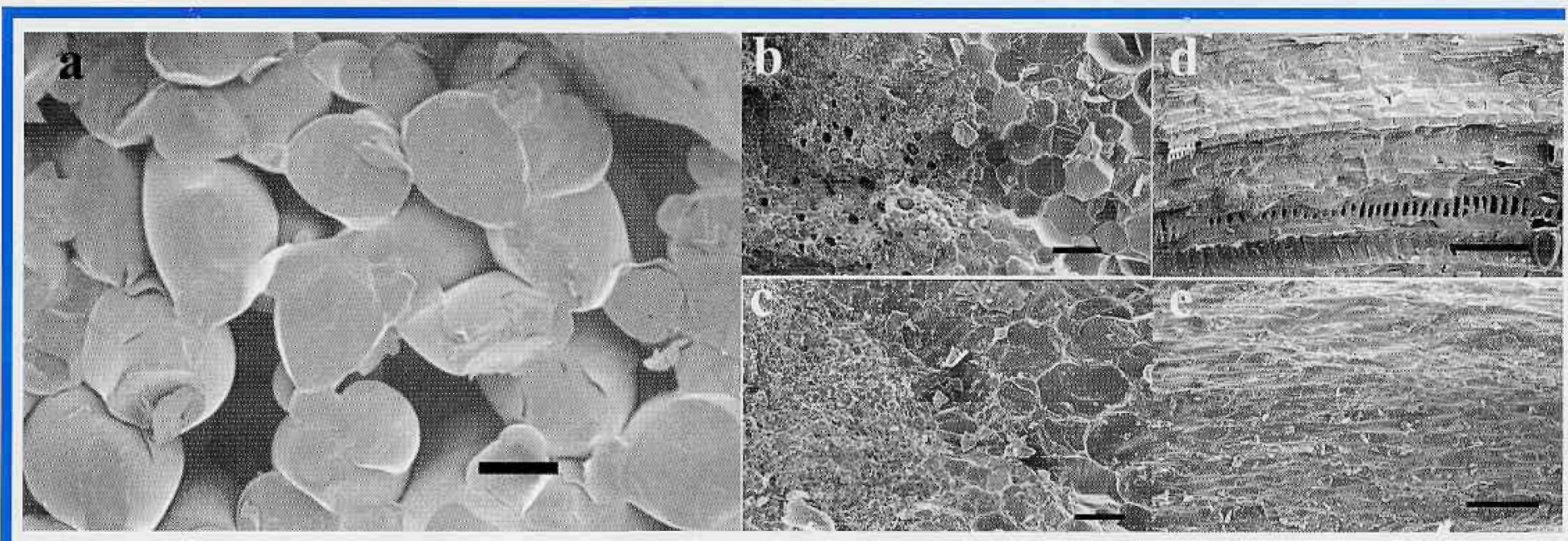

Fig 2. Cold stage scanning electron microscopy (Cryo-SEM) of fresh apple and fresh and cooked celery to visualize texture.

Cryo-SEM is a very useful technique for observing fruit and vegetable samples in the frozen-hydrated state, since they are composed of a high percentage of water.

a) freeze-fractured fresh apple flesh shows the arrangement of the cells, the degree of contact with each other, arrangement and number of air spaces, all of which affect the perception of texture. $b$-e, celery. In fresh celery, freeze-fractured in $b$ ) cross section and d) longitudinal section, the cell walls are brittle, and the fracture plane is through the cells, exposing their interiors. This is true for both the flesh (large cells) and the vascular tissues (round groups of small cells). In longitudinal section (d), the vascular elements are broken and their internal structures are visible. Upon cooking, the cell wall softens, and a break or cut will separate cells from each other $(c, e)$ rather than breaking the cells open. Microscopy clearly shows microstructural differences between the raw and cooked celery. The characteristics of the fracture plane provide information on texture and changes in these characteristics will reflect changes in mechanical properties as a result of cooking or storage. Bars $=100 \mu \mathrm{m}$

food like yoghurt). To a microscopist who is accustomed to working on biomedical samples, these food-related microstructural changes might look like sample preparation artefacts. Food microscopists must also consider structural changes in terms of the microstructural hierarchy, as related to texture and quality at each of the steps in the agri-food continuum.

\section{Can biomedical microscopy techniques be used to observe food samples?}

It has been necessary to modify standard biomedical preparation techniques to address the unique characteristics of food systems. Conventional chemical stabilization techniques were developed to stabilize cellular, protein-based biomedical samples. They cannot be used directly on food samples, because they are not effective at stabilizing these sample types. Stabilization problems exist even with foods of animal origin (meat and dairy products). Chemical fixation is a diffusion process dependent on sample composition and density; diffusion of a chemical fixative and the stabilization process is quite different in a dense matrix (cheese) versus a porous matrix (yoghurt), which is different still from a piece of tissue. Many food samples contain high levels of saturated fat, carbohydrates, water and air, which are extremely difficult or impossible to stabilize using chemical stabilization methods. Stabilization of protein-based emulsions, foams, and colloids present an additional challenge because these structures are labile and change during exposure to the stabilizing chemicals. In addition, these chemicals cannot effectively fix starch or other carbohydrates, and so have been used with plant samples with only limited success.

The movement away from chemical stabilization methods and the development of novel stabilization techniques in the biomedical field, such as low temperature preparation methods (such as cryo-fixation and low temperature scanning electron microscopy, or cryo-SEM) and microscopy methods like variable pressure scanning electron microscopy (VP-SEM) and environmental scanning electron microscopy (ESEM) allowed great progress in the preparation and observation of "difficult" food samples in their true state.

Chemical microscopy techniques, which include histological and histochemical techniques, polarizing microscopy as described by McCrone in an earlier issue of Microscopy Today, and fluorescence microscopy, are of interest to food chemists.

\section{How can you use microstructural information about food to improve it?}

Microscopy can be used to detect microstructures in food, identify interrelationships among those microstructures, and relate them to behaviour to predict food properties from microstructure.

The main aim of the agri-food industry is to provide high quality food for consumers. Microscopy can be considered to be a quality assessment tool because it can help define microstructural quality of foods. Specific microstructures, which have been associated with qualities that consumers prefer, can be used as quality indicators for each food system. Quality changes can be followed using microscopy as the food moves from production to the consumer. Microstructural changes that affect quality can result from harvesting or handling damage, the presence of insect pests and the damage that they inflict, as well as the presence of bacterial and fungal contamination of foods.

Texture is also an important quality attribute, especially to consumers of horticultural products. Microscopy tells us that changes in textural quality are paralleled by changes (usually break down) in microstructure. We can predict the texture of a food system by observing its microstructure. Storage and processing can change the microstructure and the textural quality of foods, as assessed by consumers' preferences. Food technologists and engineers rely on the relationship between textural quality and microstructure when they use microscopy. As a product development tool, microscopy can be used to guide food processors in the process of building up food microstructures that are associated with desired textures. Microscopy can help processors control the evolution of the structures, and manage changes in them during storage and distribution. This approach is used, for example, in the production of low fat products with similar properties to their full fat counterparts.

\section{What is the future of Food Structure analysis using micros- copy and imaging methods?}

Many exciting new possibilities are opening up as researchers rediscover and re-embrace microscopy, adopting microscopy 


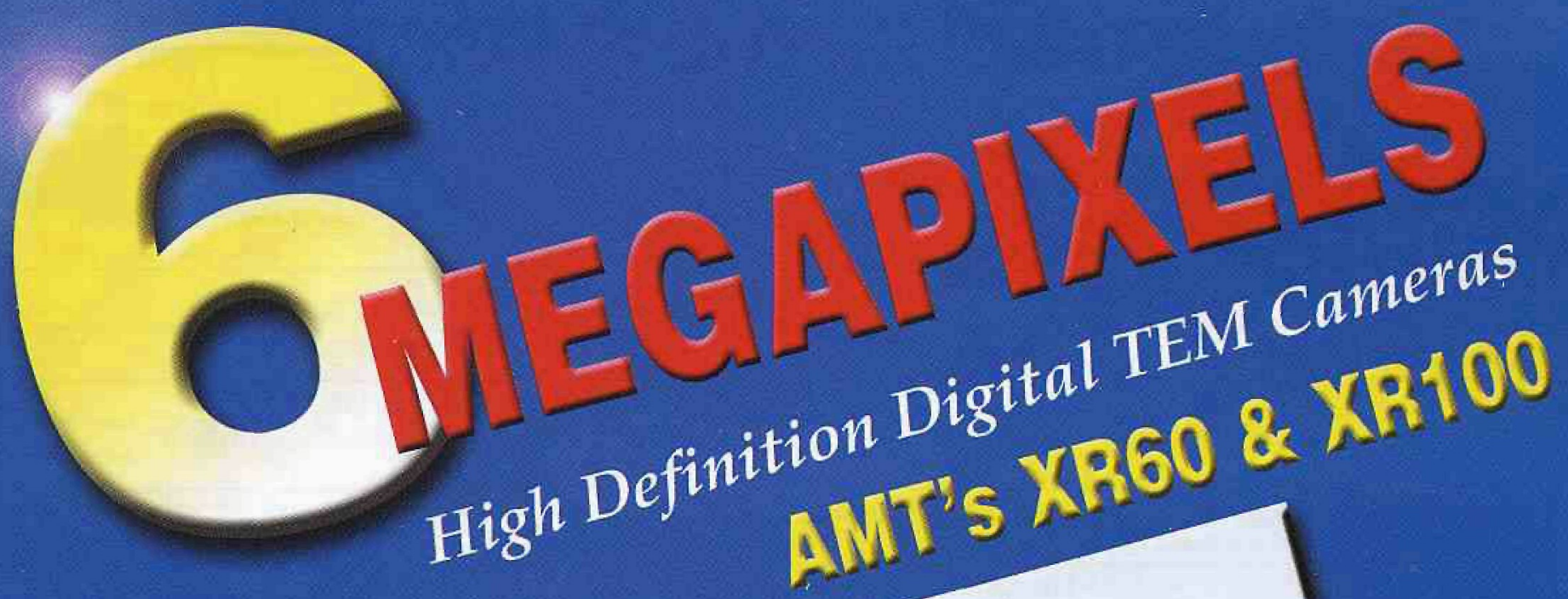
mitegantion

TEM

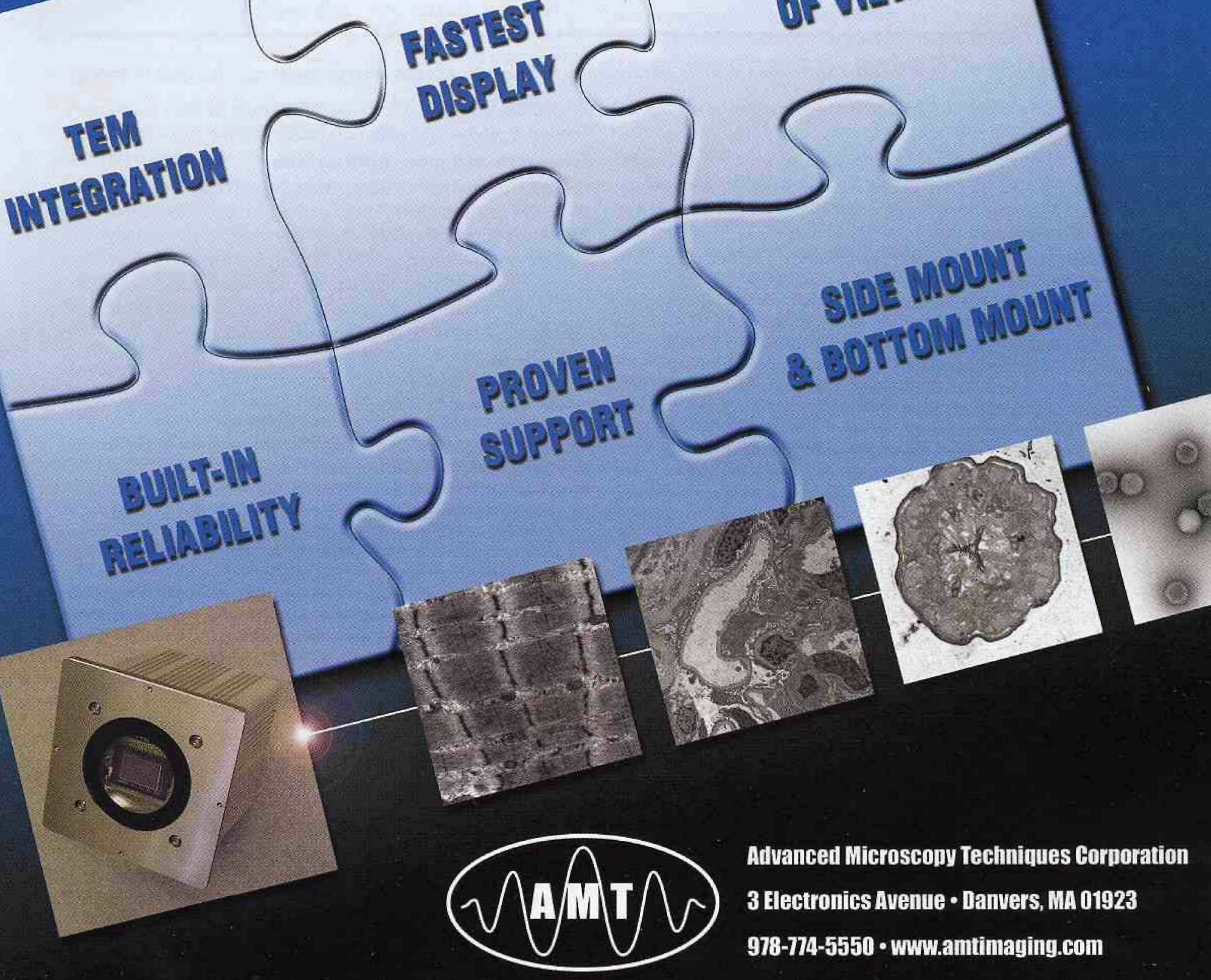




\begin{tabular}{|l|l|l|l|}
\hline $\begin{array}{l}\text { Effects of agricultural practice } \\
\text { on quality (Production of raw } \\
\text { materials) }\end{array}$ & Storage & Processing & Manufactured foods \\
\hline $\begin{array}{l}\text { Growth and rearing conditions } \\
\text { (water, nutrients, temperature, } \\
\text { light) }\end{array}$ & $\begin{array}{l}\text { Variety/breed-specific } \\
\text { characteristics (long shelf } \\
\text { life) }\end{array}$ & $\begin{array}{l}\text { Heat treatments } \\
\text { (cooking-steaming, frying, } \\
\text { canning, smoking) }\end{array}$ & $\begin{array}{l}\text { Formation of food with } \\
\text { desired texture and } \\
\text { other characteristics }\end{array}$ \\
\hline $\begin{array}{l}\text { Variety/breed-specific } \\
\text { characteristics (texture of beans, } \\
\text { meat versus dairy cattle) }\end{array}$ & Ripening and ageing & $\begin{array}{l}\text { Low temperature treatments } \\
\text { (freezing and frozen storage) }\end{array}$ & Emulsification \\
\hline Susceptibility to pests and disease & Shelf life and spoilage & $\begin{array}{l}\text { Mechanical disruption (grinding, } \\
\text { milling, chopping, comminution, } \\
\text { pureeing) }\end{array}$ & Extrusion \\
\hline $\begin{array}{l}\text { Mechanical damage due to } \\
\text { harvesting }\end{array}$ & $\begin{array}{l}\text { Assessment of pest and } \\
\text { disease control }\end{array}$ & $\begin{array}{l}\text { Chemical treatments (chemical } \\
\text { peeling, precipitation) }\end{array}$ & Tempering \\
\hline $\begin{array}{l}\text { Quality of raw materials including } \\
\text { contamination }\end{array}$ & $\begin{array}{l}\text { Effects of modified } \\
\text { atmosphere storage (gas } \\
\text { composition in storage } \\
\text { chambers) }\end{array}$ & Fermentation, pickling & Particulation \\
\hline & $\begin{array}{l}\text { Freezing and frozen storage } \\
\text { effects }\end{array}$ & $\begin{array}{l}\text { Water removal - dehydration, } \\
\text { salting }\end{array}$ & Gelation \\
\hline & Extraction, pressing & Restructuring \\
\hline
\end{tabular}

\section{Table 1. Steps in the agri-food continuum where microscopy is used to assess microstructural changes in foods.}

as a valid analytical method for foods, on par with the traditional methods.

Microscopy will continue to be used to monitor the safety and quality of food, food contact surfaces, and containers-and has expanded to include the study of forensic tampering of food and foreign body analysis.

Recognizing the limitations of chemical fixation and damage from sample preparation, food microscopists are embracing emerging techniques such as fourier transform infrared microspectroscopy (FTIR) magnetic resonance imaging (MRI) and other related technologies (Kalab, et al., 1995). These technologies, developed in the biomedical field, are based on new, non-invasive imaging methods and enable whole foods to be viewed in their native state with short specimen preparation times, with artefacts. Confocal scanning laser microscopy (CSLM) has been used by food microscopists to study samples that are fragile, or high in water or fat content. CSLM has been used us to observe dynamic processes such as the gelation of milk, which is important in the formation of products like yoghurt and cheese. New technologies such as VPSEM and ESEM also allow us to study samples high in water and fat content. Using an accessory like a tensile stage on a VP-SEM or ESEM, we can control and observe structural failure of fruit and vegetables in real time.

One of the most exciting new trends is a closer association of food microscopy with chemistry, sensory techniques and instrumental techniques in a multidisciplinary approach to defining food textural quality, called microrheology. Microrheology is a dynamic approach that uses a microscope attached to a miniaturized shear cell to view the structural failure of food products in real time (Paques and Nicolas, 2002). This equipment was designed to simulate how food would break down in the mouth of a consumer during chewing. Sensory and instrumental information describing food texture and break down using this approach are important to food manufacturers, because it is a waste of time and money to develop a product the consumer does not like and will not buy.

\section{Resources and more information:}

We have formed an international group called the Food Structure and Functionality Forum - a division of AOCS (Allan-Woitas, 2001) that meets annually and offers short courses dedicated to microscopy and imaging of food samples. Information about our group, including meetings, short courses and other activities, as well as membership and contacts for information is found at: http: //www.aocs.org/member/division/fsff/index.htm.

\section{References}

Aguilera, J.M., Stanley, D.W. (1999). Microstructural Principles of Food Processing and Engineering. 2nd edition. Aspen Publishers Inc. Gaithersburg, Maryland. $432 \mathrm{pp}$.

Allan-Woitas, P. (2001). Food Structure and Functionality Forum - a new AOCS division. Inform 12:169-175.

Allan-Woitas, P. (1999). Introduction for the special issue of the Journal SCANNING dedicated to food structure and functionality. SCANNING 21:A6

Allan-Wojtas, P., Sanford, K., McCrae, K. and Carbyn, S. (2003). An integrated microstructural and sensory approach to describe apple texture. J. Amer. Soc. Hort. Sci. 128: $381-390$.

Flint, O. 1994. Food Microscopy: a manual of practical methods using optical microscopy. Oxford: BIOS Scientific. 125pp

Kalab, M, Allan-Woitas, P, Miller, S. S. (1995). Microscopy and other imaging techniques in food structure analysis. Trends in Food Science and Technology 6: $177-186$.

Paques M., Nicolas X. (2002) Micro-rheology: preliminary results of structural behaviour of foods under deformation. In: Abstracts of the $93 \mathrm{rd} \mathrm{AOCS} \mathrm{Annual}$ Meeting and Expo, Montreal, Quebec, Canada, May 5 to 8, 2002 . p.S55

Vaughan, J.G. (1979) Food Microscopy. Academic Press, London, NY. 651 pp

White, G.W. (1970) A bibliographic history of food microscopy. J. Assoc. Publ. Analysts 8: 74-80

1. The original web site is http://anka.livstek.Ith.se:2080/microscopy / intro.htm, with alternate URLs of http:/www. magma. ca/ scimat/, or http: //distans.livstek.lth.se:2080/foodmi.htm, or http:// anka. livstek.lth.se:2080/ foodmi.htm. The original site has become so busy that alternate servers were needed. 


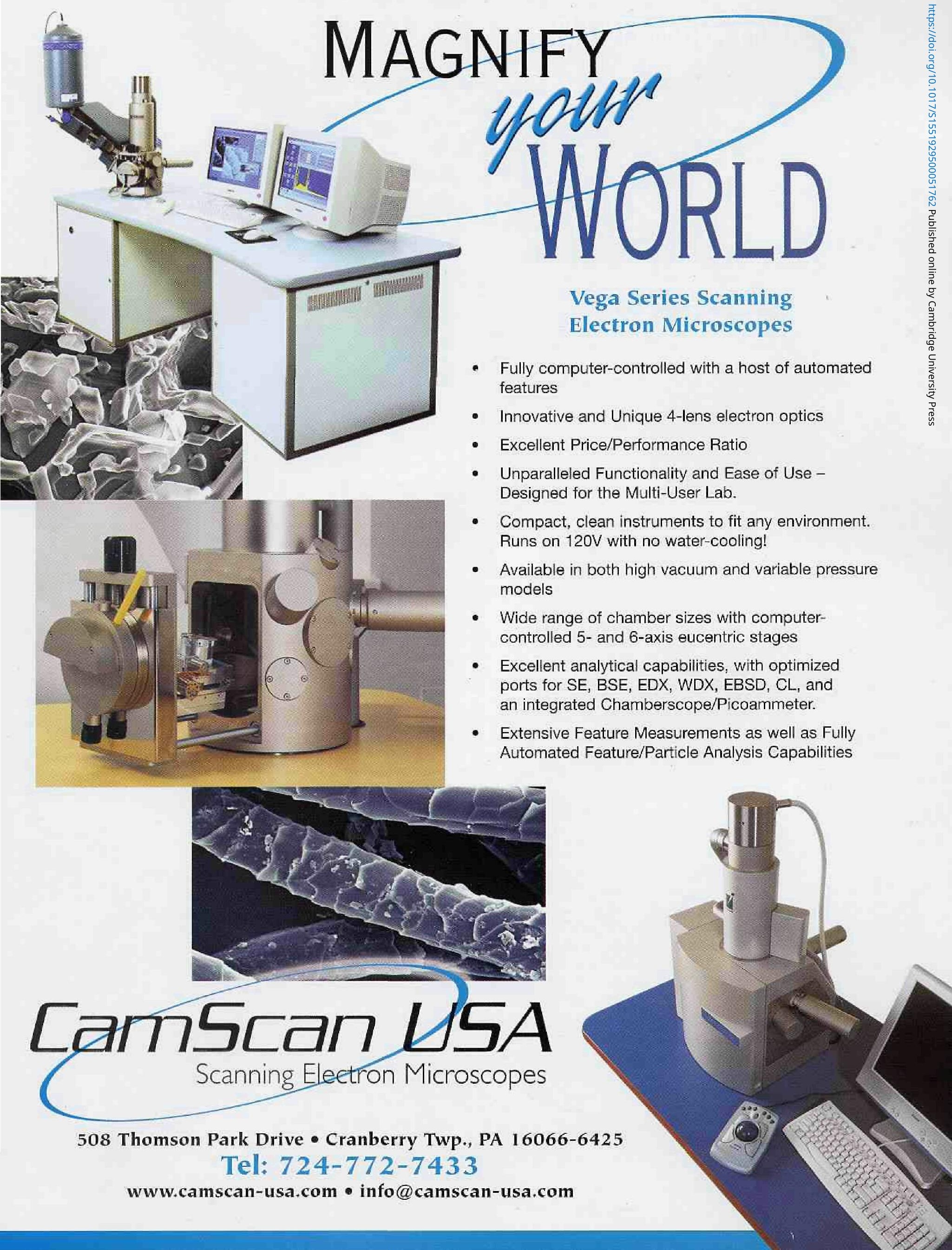




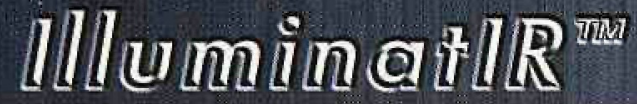

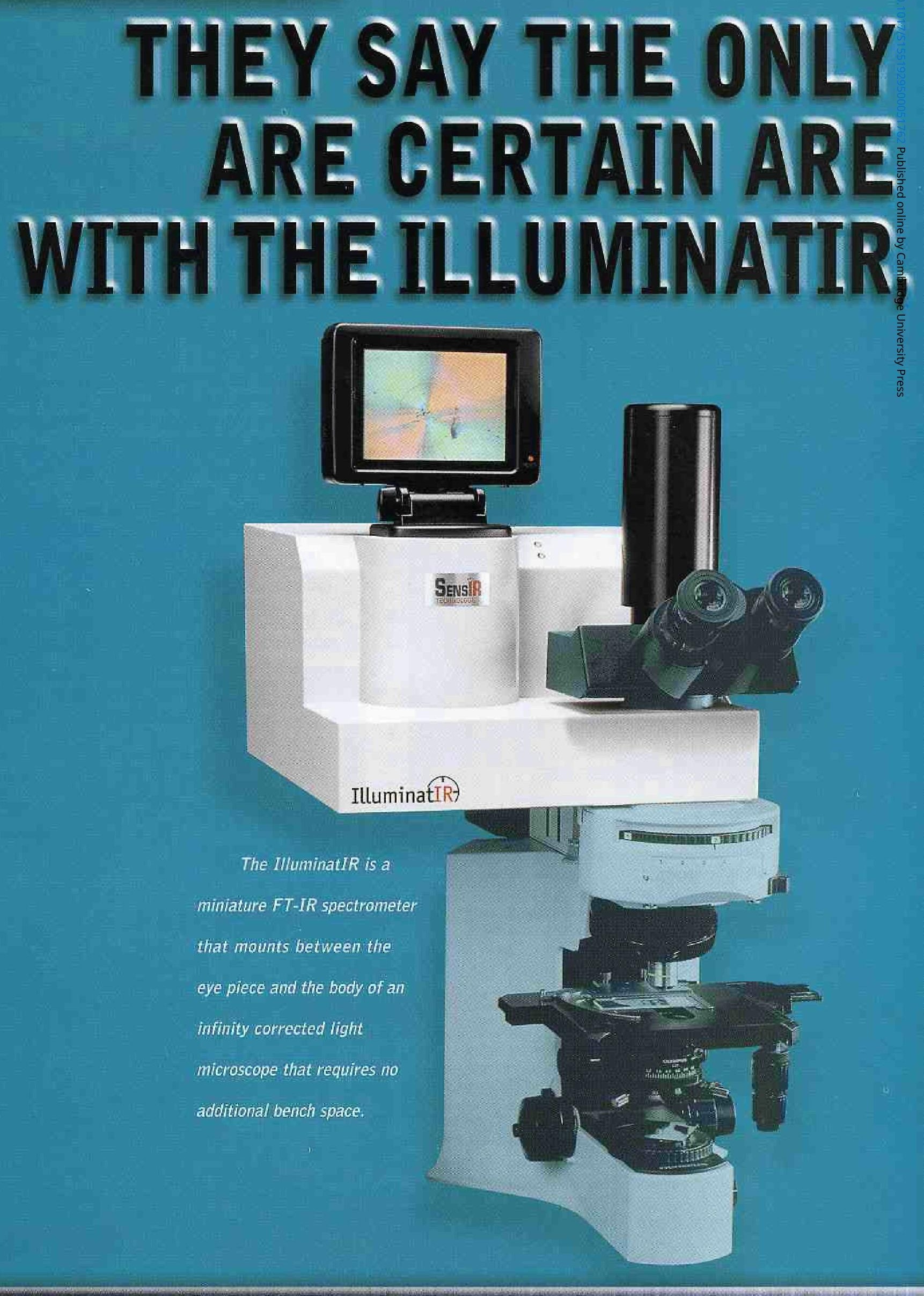




\section{THINGS IN LIFE THAT DEATH AND TAXES, THERE IS ONE MORE,}

\section{IlluminatIR adds the power of FT-IR analysis to your light microscope}

Introducing the IlluminatIR, the only miniaturized FT-IR system that attaches directly to your favorite light microscope. Add the power of molecular analysis to your visual interpretation for the most accurate and objective results.
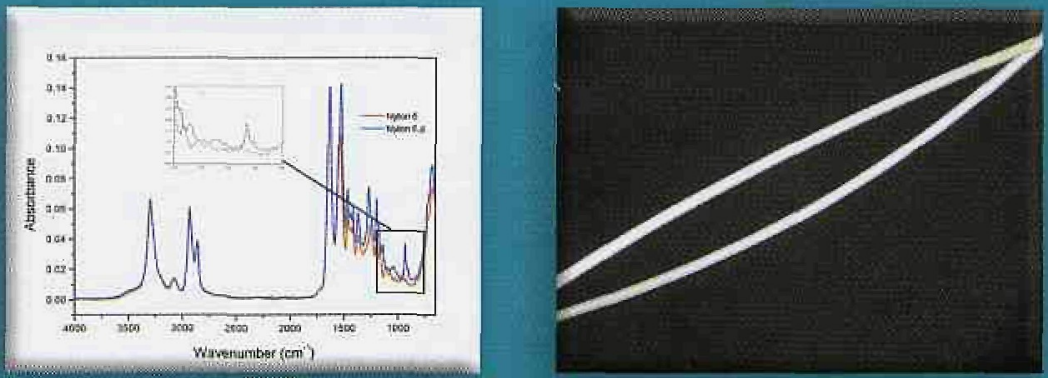

When samples are visually identical, FT-IR microscopy can show you the difference.

Visually these two nyon fiters are identical. However; when FT-IR analusis is ran on each of the fibers and their specha is averlald the difference in the wo fibers becomes dlear: The top Niber was identified as Nylon 6 and the bottom fiber to be Nylon $6 ; 6$.

Only IlluminatiR:

- provides high quality infrared data and superior visual quality

- easily attaches to infinity corrected microscopes

- maintains all the capabilities of your microscope,

i.e. polarization, fluorescence, Nomarski or image analysis, etc.

- can run FT-IR analysis simply with the turn of an objective - no need to move the sample

- adds these capabilities without taking up additional bench space

- very easy to use and maintain

The IlluminatIR: it will change the way microscopes are used forever.

\section{MAKE YOUR OWN OBJECTIVE OPINION.}

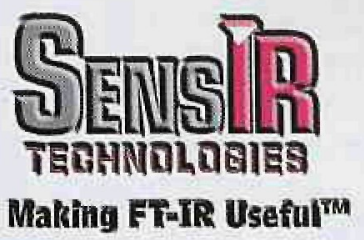

